\title{
Perspectives on Nonalcoholic Fatty Liver Disease: An Overview of Present and Future Therapies
}

\author{
John Vizuete*1 ${ }^{1}$, Alfredo Camero ${ }^{1}$, Mazyar Malakouti ${ }^{1}$, \\ Karthik Garapati ${ }^{1}$ and Julio Gutierrez ${ }^{1,2}$ \\ ${ }^{1}$ Department of Medicine, Division of Gastroenterology, University of Texas Health Science Center San Antonio, \\ San Antonio, TX, USA; ${ }^{2}$ The Texas Liver Institute, San Antonio, TX, USA
}

\begin{abstract}
Nonalcoholic fatty liver disease (NAFLD) represents a major public health epidemic. Pharmacologic therapies for this condition are scarce, but multiple agents with novel mechanisms of action are in development. Here we review the pathophysiology and natural history of NALFD, diagnostic testing and data for currently available treatment strategies. We then turn our attention to promising developmental drugs and their respective trials. As the prevalence of fatty liver disease increases, clinicians will have more tools at hand for management of this condition. We conclude the horizon is bright for patients and doctors who deal with NAFLD.
\end{abstract}

Citation of this article: Vizuete J, Camero A, Malakouti M, Garapati K, Gutierrez J. Perspectives on nonalcoholic fatty liver disease: an overview of present and future therapies. J Clin Transl Hepatol 2017;5(1):67-75. doi: 10.14218/JCTH. 2016.00061

\section{Introduction}

The importance of NAFLD cannot be overstated. It parallels the obesity epidemic within the United States (US) and is the most common hepatic disease in the western hemisphere. ${ }^{1}$ Currently the $3^{\text {rd }}$ leading indication for liver transplant, by 2030, non-alcoholic steatohepatitis (NASH) is predicted to become the most common reason for transplantation in the US. ${ }^{2}$ With an explosion of novel therapies for hepatitis $C$ virus and a relative paucity of treatment options for the spectrum of fatty liver disease, much attention has turned toward development of NASH disease modifying agents and noninvasive diagnostic tools. This article will review diagnostic options for NAFLD and highlight both traditional and novel therapeutic agents.

Keywords: Nonalcoholic fatty liver disease; Fatty liver; Steatohepatitis; NAFLD; NAFL; NASH; Developmental drugs; Hepatic steatosis.

Abbreviations: AASLD, American Association for the Study of Liver Diseases; ALT, alanine transaminase; AST, aspartate transaminase; BMI, body mass index ; CCR2/CCR5, chemokine receptor types 2 and 5; CK18, cytokeratin 18; CVC, cenicriviroc; GR-MD-02, galactoarabino-rhamnogalaturonan; HCV, hepatitis C virus; HCC, hepatocellular carcinoma; MRS, magnetic resonance spectroscopy; NAFL, nonalcoholic fatty liver; NAFLD, nonalcoholic fatty liver disease; NASH, nonalcoholic steatohepatitis; OCA, obeticholic acid; ROS, reactive oxygen species. Received: 8 November 2016; Revised: 10 February 2017; Accepted: 15 February 2017

* Correspondence to: John Vizuete, Department of Medicine, Division of Gastroenterology, University of Texas Health Science Center San Antonio, 7703 Floyd Curl Dr., San Antonio, TX 78229, USA. Tel: +1-210-737-4117, E-mail: Vizuete@ uthscsa.edu

\section{Natural history}

First introduced in 1980, NAFLD is a relatively new concept. ${ }^{3}$ It is divided into non-alcoholic fatty liver (NAFL) and nonalcoholic steatohepatitis (NASH) based on histologic findings. Biopsies of NAFL may show macrovesicular steatosis with lobular and periportal inflammation but do not demonstrate cellular injury and fibrosis (steatohepatitis), which characterizes NASH. NAFL has largely been considered benign, but recent cohort studies show a high risk for progression to $\mathrm{NASH}$ in up to $44 \%$ on serial biopsies at 5 years. ${ }^{4} \mathrm{NASH}$ causes progressive fibrosis that can lead to cirrhosis and hepatocellular cancer (HCC).

Patients with NAFL can be divided into primary (traditional obesity, insulin resistance and metabolic syndrome) and secondary causes (Wilson's disease, parenteral nutrition, medications), with primary causes being far more common. ${ }^{5}$ Patients with NASH may take a few years or decades to develop cirrhosis, and many die of alternative causes before progressing. Rate of progression does not correlate with body mass index (BMI) or hyperlipidemia. ${ }^{6}$ Instead, risk factors for more aggressive disease include the presence of diabetes, Hispanic ethnicity, and microvesicular steatosis on biopsy. ${ }^{7}$ Left alone, NASH results in progressive fibrosis and is an under-recognized cause of cryptogenic cirrhosis. ${ }^{8}$ Cirrhosis of any kind is a risk factor for HCC, and cirrhosis from NASH is no exception. Following the trend of obesity and metabolic syndrome, HCC is the fastest growing cancer type in the US. ${ }^{9}$

\section{Epidemiology}

NAFLD is associated with visceral obesity and diabetes. It has mirrored the epidemiologic course of obesity in the US and is detected in $73-90 \%$ of obese individuals on biopsy. ${ }^{10,11}$ About $1 / 3$ of the US population are estimated to have NAFL. By most estimates, NASH comprises about $15 \%$ of all NAFLD and $3-5 \%$ of the American population. Hospitalizations for NAFLD have increased by $97 \%$ since the year $2000 .^{12}$

\section{Pathophysiology}

The pathophysiology of NAFLD is complex and includes numerous genetic, dietary, metabolic and hormonal factors. Although most experts theorize a two-hit model to explain the progression from NAFL to NASH, new insight suggests a multiple hit hypothesis. ${ }^{13,14}$ The first hit refers to insulin resistance, resulting in increased fat accumulation within the hepatocyte (steatosis). With the background of increased 
Vizuete J. et al: Present and future therapies for NAFLD

liver fat, hepatocytes are vulnerable to multiple pathophysiologic processes resulting in lipid oxidation, including impaired hepatocyte apoptosis and cytokine activity. ${ }^{15} \mathrm{~A}$ genetic basis for the first hit has been proposed, citing abnormalities in lipid transporters and hormonal regulators, like leptin and adiponectin, in certain populations. ${ }^{16}$ Dietary carbohydrate intake, insulin resistance, metabolic syndrome, and certain medications all inhibit the reduction of reactive oxygen species (ROS) and represent potential "hits" in a susceptible individual. ${ }^{17}$ Insulin resistance predicts fibrosis independent of ethnicity, but although the prevalence of diabetes is highest among African Americans, the burden of NASH most disproportionately affects the Hispanic population. This line of evidence suggests that insulin resistance is not the only variable involved. ${ }^{18}$ Identification of various factors conferring increased risk of the development of NASH has offered potential targets for treatment.

\section{Diagnosis}

The diagnosis of NAFLD has 3 requirements:

1. Demonstration of hepatic steatosis by imaging or biopsy;

2. Exclusion of significant alcohol consumption, $>30 \mathrm{~g} /$ day for men and $>20 \mathrm{~g} /$ day for women within the past years;

3. Exclusion of other causes of hepatic steatosis. ${ }^{19}$

In most patients undergoing evaluation, radiologic and laboratory findings are sufficient to make the diagnosis of NAFLD; however, liver biopsy is the gold standard for diagnosis of NASH.

\section{Laboratory testing}

In patients with suspected NAFLD, the serum aminotransferases are usually abnormal; however, the combination of imaging consistent with hepatic steatosis and an elevated alanine aminotransferase (ALT) raises concern for NASH. The degree of liver enzyme elevation does not predict the degree of hepatic inflammation nor fibrosis, and a normal ALT level does not exclude clinically important histologic injury. ${ }^{20}$ The aminotransferase levels are usually mildly to moderately elevated and the ratio of aspartate aminotransferase (AST)/ALT is often $<1$, but this ratio increases as the fibrosis advances. Mildly elevated serum ferritin is common in patients with NAFLD. Common alternative causes of hepatic steatosis, such as alcoholic liver disease, hepatitis C, medications, parental nutrition, Wilson's disease, hemochromatosis, autoimmune liver disease, lysosomal acid lipase deficiency and severe malnutrition, must be excluded. ${ }^{21}$

\section{Cytokeratin 18 (CK18)}

Although not widely used in clinical practice, CK18 represents a promising biomarker for assessment of the presence of $\mathrm{NASH}$. CK18 is a filament protein found in hepatocytes that is released upon apoptosis. A defining feature of NASH is cell death, and serum CK18 levels have been shown to correlate with steatohepatitis in numerous trials, with a pooled sensitivity of $78 \%$ and specificity of $87 \%$, effectively differentiating NASH from NAFL. ${ }^{22}$ Especially when utilized in high-risk individuals, CK18 can represent a cost-effective diagnostic tool. ${ }^{23}$ As the cost of the assay decreases, this test may find a foothold in routine practice and mitigate the need for liver biopsy.

\section{Imaging}

Various imaging modalities can demonstrate fatty infiltration of the liver, but no radiographic study to date has been shown to differentiate between the histologic subtypes of NAFL and $\mathrm{NASH}$. Ultrasound often reveals a hyperechoic texture consistent with fatty infiltration, having reported sensitivity and specificity of about $85 \%$ and $94 \%$ for NAFL and NASH, respectively. ${ }^{24}$ The sensitivity of ultrasonography decreases in the case of obesity. ${ }^{25}$ Computed tomography (CT), magnetic resonance imaging (MRI), and magnetic resonance spectroscopy (MRS) can identify steatosis but are not sufficiently sensitive to detect inflammation or fibrosis. ${ }^{26}$ Unlike CT and MRI, MRS allows for quantification of hepatic fat, and may be particularly helpful in patients with small amounts of hepatic steatosis. ${ }^{27}$

\section{Noninvasive tests for liver fibrosis}

Estimating hepatic fibrosis in an individual with NAFLD may provide the clinician guidance as to the need for liver biopsy. Multiple serologic tests have been shown as effective for predicting fibrosis, and these include AST/ALT ratio, AST/ platelet ratio, BARD score, enhanced liver fibrosis panel, fibrosis-4 (FIB-4) index, FibroTest (FibroSure), and fibrometer. Serologic tests for fibrosis have an average sensitivity of $47 \%$ and a specificity of $90 \% .{ }^{28}$ Hepatic elastography (FibroScan device, Echosens, Paris, France) is a rapid and non-invasive measure of hepatic stiffness. For this procedure, a probe produces an elastic wave through the liver and the speed of wave is measured 2.5 to $6.5 \mathrm{~cm}$ away from skin. This test is being used more commonly as a proxy for liver biopsy and is reliable for detection of the presence or absence of fibrosis, with a sensitivity of $76 \%$ and specificity of $85 \% .^{29}$ This test is becoming increasingly available, shows low intraobserver discordance, and with proper training can maintain accuracy even in obese patients. ${ }^{30}$ However, we maintain that patients with NAFLD who are at increased risk for steatohepatitis or those with competitive etiologies for liver disease should be considered for biopsy.

\section{NAFLD activity score (NAS)}

The NAS is a validated scoring system used to grade disease severity in patients with NAFLD. ${ }^{31}$ The NAS is the sum of the biopsy's individual scores for steatosis (0 to 3 ), lobular inflammation (0 to 3), hepatocellular ballooning (0 to 2 ), and fibrosis ( 0 to 4 ). An NAS of 1 or 2 corresponds to NAFL, 3 or 4 corresponds to borderline $\mathrm{NASH}$, and $\geq 5$ corresponds to NASH (Table 1).

\section{Treatment}

Although all patients with NAFLD should receive thoughtful clinical and supportive care, patients with NASH should be treated more aggressively, due to the natural course of this disease. Traditional treatments for NAFLD have targeted associated comorbidities, such as obesity, hyperlipidemia and insulin resistance, with varying degrees of success. 
Table 1. NAS scoring system

\begin{tabular}{ll}
\hline Steatosis & S score \\
$<5 \%$ & 0 \\
$5-33 \%$ & 1 \\
$34-66 \%$ & 2 \\
$>66 \%$ & 3 \\
Lobular inflammation & L score \\
None & 0 \\
$<2$ foci/200 x & 1 \\
$2-4$ foci/200 x & 2 \\
$>4$ foci/200 x & 3 \\
Hepatocyte ballooning & B score \\
None & 0 \\
Few ballooned cells & 1 \\
Many ballooned cells & 2 \\
\hline
\end{tabular}

NAS components: Grade $=$ Total score: $\mathrm{S}+\mathrm{L}+\mathrm{B}$. Range, $0-8$.

\section{Lifestyle Changes}

Despite the many therapeutic agents studied for the treatment of $\mathrm{NASH}$, there currently remains no FDA approved regimen for this disease. Lifestyle modifications including diet, exercise and weight loss remain the cornerstone of NASH management. Several randomized trials have demonstrated that successful lifestyle interventions focused on healthy eating and exercise habits that yield subsequent weight loss result in histologic improvement in NAS scores. Promrat et al. ${ }^{32}$ showed that patients who were able to lose $7 \%$ of their baseline body weight had significant improvements in steatosis, lobular inflammation, ballooning injury and NAS score compared to those who did not lose weight. Likewise, Belfort and Harrison ${ }^{33}$ demonstrated histologic improvement in patients who lost $9 \%$ of their baseline weight. Although weight loss of $5 \%$ resulted in improvement in insulin sensitivity, it did not significantly improve the NAS score. Based on these findings, we recommend a weight loss goal of at least $5-10 \%$ over 6 months.

Unfortunately, achieving weight loss is not always tenable. Aerobic and resistance training has been shown to improve lipid profile in those with NAFLD, but when this regimen is not accompanied by significant weight loss there appears to be no improvement in NAS score. ${ }^{34}$ It appears that diets rich in fruits, vegetables, low glycemic index items and high fiber foods, with minimal saturated fats, simple carbohydrates and sweetened drinks, (the Mediterranean diet) may be the best universal recommendations for NAFLD patients. ${ }^{35}$ Although moderate alcohol consumption may have other beneficial effects, we generally recommend alcohol avoidance for these patients.

\section{Bariatric surgery}

Given the importance of weight loss, the effects of bariatric surgery on the natural history of NAFLD have been reported by numerous groups. Meta-analyses show that various bariatric surgical modalities yielding loss of $20 \%$ to $40 \%$ of baseline BMI result in significant histologic improvement. ${ }^{36}$
Some patients experience complete resolution of NASH. The data are promising, but are by nature descriptive and mostly retrospective; moreover, controlled trials are lacking. A small percentage of patients experience continued fibrosis despite weight loss surgery. Given the lack of randomized control trials, bariatric surgery cannot yet be recommended as firstline therapy for the treatment of $\mathrm{NASH}$; although, many patients harbor alternative indications for weight loss surgery.

\section{Liver transplantation}

$\mathrm{NASH}$ is currently the third most common indication for liver transplantation in the US and is predicted to become the most common indication within the next two decades. ${ }^{37}$ From 2001 to 2009 , the percentage of patients undergoing liver transplant for NASH increased from $1.2 \%$ to $9.7 \% .{ }^{38}$ Fortunately, NASH patients appear to have excellent post-transplant outcomes. Their survival rates at 1,3 and 5 years following transplant are higher than those for patients with $\mathrm{HCC}$, hepatitis $\mathrm{C}$ virus (HCV), alcoholic liver disease, acute hepatic necrosis, hemochromatosis or cryptogenic cirrhosis. ${ }^{39}$ However, it should be noted that death in NASH patients up to 10 years following transplantation was most often due to cardiovascular disease. Although more investigation is needed to understand recurrent disease in these patients, cirrhosis from NASH remains a class I-A indication for transplantation.

\section{Medications}

\section{Orlistat}

Given the evidence in support of weight loss therapy for the treatment of $\mathrm{NASH}$, agents for weight loss have been studied for their potential role in the management of NAFLD. Orlistat is a reversible lipase inhibitor and prevents enteric lipid absorption. Harrison et al. ${ }^{40}$ compared orlistat to placebo in 55 obese patients with NASH; both groups were also treated with vitamin $\mathrm{E}$ and dietary restriction for 36 weeks. The orlistat treatment did not result in significant weight loss compared to placebo $(8.3 \%$ vs $6.0 \%, p=0.3)$ and both groups were found to have improvement in insulin sensitivity, adiponectin, steatosis, ballooning, inflammation and NAS scores compared to baseline. When stratified according to weight loss, those patients who had lost $>5 \%$ of their body weight exhibited improved insulin sensitivity and reduction in steatosis, while those patients who had lost $9 \%$ of their baseline body weight noted additional histological improvement in ballooning, inflammation and NAS scores compared to those who did not. The orlistat therapy was not associated with improved clinical endpoints compared to placebo. In other trials, orlistat has been shown to significantly decrease liver enzymes and improve steatosis on ultrasound compared to placebo. ${ }^{41}$ However, the beneficial effects in these trials appear to be related primarily to weight loss rather than medication exposure. It is not clear if orlistat yields sustained long-term weight loss, and its use is limited by gastrointestinal side effects. More well-powered studies are needed to determine if orlistat has a role in the treatment of NASH.

\section{Metformin}

Given the association of insulin resistance and NAFLD, insulinsensitizing agents have garnered much interest in the management of the condition. Data for metformin have been 
Vizuete J. et al: Present and future therapies for NAFLD

variable, with some studies demonstrating improvement in aminotransferase levels and histology and others showing no significant difference of any kind. ${ }^{42,43}$ Most data are limited by small sample size or poor design, with non-controlled trials existing in the literature. ${ }^{44,45}$ Even larger trials have failed to demonstrate that metformin improves clinical outcomes or liver histology, although it has appeared to influence circulating hormones like adiponectin. ${ }^{46,47}$ Although metformin is generally well tolerated, there is insufficient evidence at this time to include it in our arsenal against $\mathrm{NASH}$, however, one systematic review concluded that in diabetic populations, it may reduce the incidence of $\mathrm{HCC}$ and cholangiocarcinoma. ${ }^{48}$

\section{Thiazolidinediones}

Rosiglitazone and pioglitazone have been studied in a series of trials for NASH. Due to increased cardiovascular adverse events associated with rosiglitazone, pioglitazone is the only accessible agent in the US. In the FLIRT trial, 1 year of treatment with rosiglitazone demonstrated improvement in steatosis and transaminase levels compared to placebo. ${ }^{49} \mathrm{~A}$ larger study of 247 patients conducted over 2 years compared pioglitazone to vitamin $\mathrm{E}$ and placebo, with the primary outcome of composite improvement on histology at 96 weeks. ${ }^{50}$ Pioglitazone showed a strong trend toward the primary outcome but did not achieve statistical significance over placebo. Vitamin E therapy, on the other hand, resulted in improved histology compared to placebo. Pioglitazone did show benefit in several independent subcategories including reduction in steatosis, inflammation and hepatocyte ballooning, as well as in AST/ALT levels. There is concern that histologic changes associated with pioglitazone may not be sustained after discontinuation. In addition, a significant percentage of the pioglitazone group gained weight (avg $4.7 \mathrm{~kg}$ ) compared to the vitamin E or placebo group. Meta-analyses have shown that pioglitazone improves inflammation (and steatosis) but has a limited effect on fibrosis. ${ }^{51}$ The American Association for the Study of Liver Diseases (AASLD) currently promotes the use of pioglitazone in the treatment of NASH; however, we use it for diabetic patients who have an additional indication, given the limited evidence and long-term safety concerns.

\section{Vitamin E}

Oxidative stress is thought to be a key component in the pathogenesis of NASH (i.e. the "second hit") and has also been targeted for therapeutic endeavors. In the PIVENS study discussed above, vitamin E treatment resulted in statistically significant improvement in steatohepatitis, serum transaminases and lobular inflammation. Although improvement in fibrosis was not demonstrated, vitamin E therapy has a low incidence of adverse events. Conversely, the TONIC trial did not demonstrate sustained reduction in liver chemistries nor improvement in histological features. ${ }^{46}$ Still, vitamin E is currently recommended at a dose of $800 \mathrm{IU} /$ day for non-diabetic adults with biopsy-proven NASH. It should be noted that one large meta-analysis of 68 randomized clinical trials noted a significantly increased risk of all-cause mortality for antioxidant supplements including vitamin $\mathrm{E}$; although, subsequent meta-analyses have not drawn the same conclusions, and the biologic mechanism for such an outcome is not well established. ${ }^{52,53}$ We use vitamin $\mathrm{E}$ in nondiabetic patients with NASH given its tolerability and effects comparable to pioglitazone.

\section{Statins}

Dyslipidemia is closely associated with metabolic syndrome, but the consequences of dyslipidemia in NAFLD have not been well elucidated. In preliminary studies, atorvastatin appeared to improve liver chemistries, as well as steatosis. ${ }^{54}$ As there is no evidence to demonstrate serious risk of liver injury associated with concurrent statin use in NAFLD, statins are an important consideration for the management of dyslipidemia in NAFLD patients. ${ }^{55}$ Moreover, statins have been associated with a lower risk of HCC in patients with cirrhosis. ${ }^{56}$ Statins are not recommended as primary therapy for NASH but should be used in patients with concomitant dyslipidemia or cirrhosis.

\section{Omega-3 fatty acids}

As with the other novel agents for the treatment of NASH, few large, controlled studies exist which have thoroughly assessed the effects of omega-3 fatty acids in the NAFLD population. A recent meta-analysis conducted by Parker et al., 57 noted improvement in hepatic lipid deposition without significant change in liver chemistries. However, the results of the WELCOME trial have been reported and indicate an improvement in steatosis on MRS with 15-18 months of treatment with docosahexaenoic acid plus eicosapentaenoic acid compared to placebo. ${ }^{58}$ All over-the-counter omega acids are not equal but are generally well tolerated with minimal adverse side effects. We believe there may be a role for omega acids in the treatment of $\mathrm{NASH}$, but further high quality studies are needed before firm recommendations can be given. Numerous other conventional agents, including ursodeoxycholic acid and pentoxyfylline, have been tested for the treatment of $\mathrm{NASH}$, typically in small nonrandomized cohorts, and are not recommended at this time.

\section{Clinical trials/new pharmaceuticals}

With few efficacious pharmacologic treatments for NAFLD and $\mathrm{NASH}$, attention has turned to the development of agents with novel mechanisms of action. Targets of these pharmacologic treatments include improving lipid metabolism and insulin sensitivity in hepatocytes, decreasing hepatocyte death by inhibiting apoptosis, and decreasing inflammatory responses to injury. Most trials use the primary endpoint of improvement in liver histology but secondary endpoints, including improvement in transaminases, inflammatory markers and markers of fibrosis, are of interest as well. See Table 2 for a list of agents currently under investigation in human subjects for the treatment of NAFLD and NASH.

\section{Elafibranor}

Elafibranor (GFT505) is a novel dual peroxisome proliferatoractivated receptor (PPAR) alpha/delta agonist, similar to the thiazolidinediones, which are PPAR gamma agonists. PPAR alpha/delta are nuclear receptors expressed highly in hepatocytes with extensive enterohepatic circulation. They play a major role in fatty acid transport, beta-oxidation, modulating gluconeogenesis and inflammatory responses. ${ }^{59,60}$ In murine models, treatment with elafibranor resulted in improvement in liver dysfunction markers, decreased hepatic lipid accumulation and inhibited pro-inflammatory and pro-fibrotic gene expression. Mice also exhibited a decrease in the progression 
Vizuete J. et al: Present and future therapies for NAFLD

Table 2. Summary of preclinical agents

\begin{tabular}{|c|c|c|c|}
\hline Drug & Mechanism of action & Primary endpoint studied & Results \\
\hline $\begin{array}{l}\text { Elafibranor } \\
\left(_{(G F T 505)^{62}}\right.\end{array}$ & $\begin{array}{l}\text { Dual peroxisome proliferator- } \\
\text { activated receptor (PPAR) } \\
\text { alpha/delta agonist = play } \\
\text { role in hepatocyte fatty acid } \\
\text { metabolism, modulating } \\
\text { gluconeogenesis and } \\
\text { inflammatory responses }\end{array}$ & $\begin{array}{l}\text { NASH reversal without worsening } \\
\text { of fibrosis - evaluated by } \\
\text { post-treatment biopsy }\end{array}$ & $\begin{array}{l}\text { Post-hoc analysis using a more } \\
\text { stringent response criteria } \\
\text { demonstrated a response rate of } \\
19 \% \text { vs. } 12 \% \text { when compared to } \\
\text { placebo }(p=0.045)\end{array}$ \\
\hline $\begin{array}{l}\text { Obeticholic } \\
\text { acid (OCA) }\end{array}$ & $\begin{array}{l}\text { Potent activator of the farnesoid } \\
X \text { receptor and promotes insulin } \\
\text { sensitivity and decreased hepatic } \\
\text { gluconeogenesis and circulating } \\
\text { triglycerides }\end{array}$ & $\begin{array}{l}\text { Improvement in NAS score by }>2 \\
\text { points without worsening of } \\
\text { fibrosis - evaluated by } \\
\text { post-treatment biopsy }\end{array}$ & $\begin{array}{l}\text { Improvement in NAS score by }>2 \\
\text { points occurred in } 45 \% \text { of } \\
\text { patients taking OCA vs. } 21 \% \text { in } \\
\text { the placebo group ( } p=-0002)\end{array}$ \\
\hline Emricasan 70 & $\begin{array}{l}\text { Irreversible pan-caspase } \\
\text { inhibitor avid in hepatocytes } \\
\text { preventing apoptosis of steatotic } \\
\text { hepatocytes, resulting in } \\
\text { decrease fibrotic properties }\end{array}$ & $\begin{array}{l}\text { Phase } 2 \text { clinical trial - "evaluate } \\
\text { the effect of emricasan in } \\
\text { subjects with NAFLD and } \\
\text { elevated ALT" }\end{array}$ & $\begin{array}{l}\text { Mean absolute reduction in ALT } \\
\text { from baseline at } 28 \text { days }-25.8 \\
\text { vs. } 9.4(p=<0.05)\end{array}$ \\
\hline Aramchol $^{73}$ & $\begin{array}{l}\text { Novel synthetic lipid molecule } \\
\text { that acts on inhibition of the } \\
\text { stearoyl-coenzyme A desaturase } \\
1 \text { activity, thereby decreasing the } \\
\text { synthesis and increases the beta- } \\
\text { oxidation of fatty acid }\end{array}$ & $\begin{array}{l}\text { Difference in liver fat content, } \\
\text { measured by magnetic } \\
\text { resonance spectroscopy }\end{array}$ & $\begin{array}{l}\text { High-dose aramchol } \\
\text { demonstrated a significant } \\
\text { reduction of } 12.57 \% \pm 22.14 \text { vs. } \\
\text { a } 6.39 \% \pm 36.27 \text { increase in } \\
\text { placebo group }(p=0.02)\end{array}$ \\
\hline Cenicriviroc $^{82}$ & $\begin{array}{l}\text { Antagonist of CCR2/CCR5, which } \\
\text { are implicated in liver } \\
\text { inflammation and fibrosis and are } \\
\text { thought to aid in the treatment of } \\
\text { NASH by decreasing recruitment, } \\
\text { migration and infiltration of pro- } \\
\text { inflammatory monocytes to the } \\
\text { site of liver injury, resulting in } \\
\text { anti-fibrotic properties }\end{array}$ & $\begin{array}{l}\text { Drop in NAS by } \geq 2, \text { with at least a } \\
1 \text {-point improvement in more } \\
\text { than one category and with no } \\
\text { concurrent worsening of fibrosis } \\
\text { stage }\end{array}$ & To be determined \\
\hline GR-MD-02 ${ }^{87}$ & $\begin{array}{l}\text { Complex carbohydrate that binds } \\
\text { to galectin- } 3 \text { protein, which is } \\
\text { expressed in immune cells and in } \\
\text { inflammatory states, resulting in } \\
\text { anti-fibrotic properties }\end{array}$ & Not yet released & Not yet released \\
\hline
\end{tabular}

of established fibrosis, along with accelerated liver recovery. ${ }^{61}$ In a recently published phase III randomized controlled trial, Ratziu et al. ${ }^{62}$ compared elafibranor ( $80 \mathrm{mg}$ and $120 \mathrm{mg}$ ) to placebo administered over 1 year in patients with noncirrhotic NASH. The primary endpoint of resolution of NASH without worsening of fibrosis on post-treatment biopsy was not significant compared to placebo. However, a post-hoc analysis of the modified secondary outcome (including a stricter definition of NASH reversal) revealed a significant improvement in the high-dose elafibranor group (19\% vs. $12 \%, p=0.045$ ) compared to placebo. Subgroup analyses demonstrated that patients with higher NAS scores $(>4)$ demonstrated greater improvement in histology in response to $120 \mathrm{mg}$ elafibranor compared to those with mild disease. Liver function tests, lipid parameters and diabetic parameters were improved in patients taking either dose of elafibranor. Elafibranor was also well tolerated, although there was a reversible increase in serum creatinine.

\section{Obeticholic acid (OCA)}

OCA is a synthetic variant of the natural bile acid chenodeoxycholic acid, and is a potent activator of the farnesoid $X$ nuclear receptor. It promotes insulin sensitivity and decreases hepatic gluconeogenesis and circulating triglycerides. ${ }^{63}$ Mudaliar et $a l .{ }^{64}$ demonstrated that administration of OCA in patients with diabetes and NAFLD increased insulin sensitivity and reduced steatosis and lobular inflammation after only 6 weeks of therapy. Of note, this drug is the first pharmacologic agent shown to reduce fibrosis. In the FLINT trial, Neuschwander-Tetri et al. ${ }^{65}$ showed that 72 weeks of OCA (25 mg) was superior to placebo in patients with biopsy evidence of NASH (NAS >4). Forty-five percent of the patients in the OCA treatment group had improved liver histology of 2 NAS points or greater compared to $21 \%$ in the placebo group $(p=0.0002)$. However, the proportion of patients with complete resolution of NASH did not significantly differ between the two groups ( $22 \%$ vs. $13 \% ; p=0.08)$. Serum levels of ALT 
and gamma-glutamyl transpeptidase were decreased in the OCA treatment group compared to the placebo group. Adverse effects included pruritis and drug-associated dyslipidemia. OCA was in phase III trials at the time of this writing, and will likely be the first next-generation drug approved for $\mathrm{NASH}$. It is also under study for the treatment of primary biliary cirrhosis and has been shown to improve liver associated enzymes in that case population. ${ }^{66}$

\section{Emricasan}

Emricasan is an irreversible pan-caspase inhibitor that is orally active and retained in the liver. ${ }^{67}$ Caspases play an important role in apoptosis and it has been demonstrated that steatotic hepatocytes undergo apoptosis. ${ }^{68}$ Preclinical models showed that treatment with emricasan in mice with high-fat diets resulted in decreases in AST/ALT levels, NAS histological score and inflammatory markers. Mice treated with emricasan also showed reduction in hepatic fibrosis by decreasing fibrosis score, fibrosis seen by staining techniques, and measurement of alpha-smooth muscle actin. This was achieved without altering any of the metabolic syndrome parameters (hyperglycemia, hyperinsulinemia, hypercholesteremia) or liver fat content, thus suggesting that this medication may be a potential option aimed solely at treatment of fibrosis rather than steatosis or metabolic markers. ${ }^{69}$ The first randomized trial used emricasan at $25 \mathrm{mg}$ administered twice a day in 38 patients, and found statistically significant reductions in AST/ALT $(p<0.05)$ and CK18/M30 compared to placebo. ${ }^{70}$ Further trials with histologic endpoints are warranted, particularly using emricasan as adjunctive therapy to metabolically active agents in patients with NASH and fibrosis.

\section{Aramchol}

Aramchol is a novel synthetic lipid molecule obtained by conjugating cholic acid and arachidic acid that has been shown to reduce hepatic fat content in animals with a highfat diet. ${ }^{71}$ It has been shown to inhibit the stearoyl-coenzyme A desaturase 1 activity, thereby decreasing the synthesis and increasing the beta-oxidation of fatty acids in vitro. ${ }^{72}$ Safadi et $a .^{73}$ performed a randomized, double-blinded, placebocontrolled clinical trial of patients with biopsy-proven NAFLD, examining change in liver fat content with low $(100 \mathrm{mg})$ or high $(300 \mathrm{mg}$ ) dose aramchol administered over 12 weeks. A dose response relationship was observed with the higher dose aramchol arm; specifically, a significant decrease was found in liver fat content, as evaluated by MRS $(p=0.02)$. No other secondary endpoints in this study were statistically significant. Trials with a longer duration of treatment may be needed to clarify potential effects of this agent.

\section{Cenicriviroc (CVC)}

CVC is a novel, oral antagonist of the dual C-C chemokine receptor types 2 and 5 (CCR2/CCR5). CCR2/CCR5 are implicated in liver inflammation and fibrosis, and are thought to aid in the treatment of NASH by decreasing recruitment, migration and infiltration of pro-inflammatory monocytes to the site of liver injury induced by activated Kupffer cells, mainly via CCR2 antagonism and resulting in anti-fibrotic properties. ${ }^{74-81}$ A large multinational phase IIB trial, dubbed CENTAUR is ongoing and has a primary composite endpoint of histologic improvement (decreasing NAS by $\geq 2$, with at least a 1 -point improvement in more than one other category and no concurrent worsening of fibrosis). ${ }^{82}$ Interestingly, this medication is also being investigated for treatment of human immunodeficiency virus type 1 infections and has completed phase II trials for that indication. ${ }^{83}$ We eagerly await the results of CENTAUR.

\section{Galactoarabino-rhamnogalaturonan (GR-MD-02)}

GR-MD-02 has recently been described as a potential target in therapy against fibrosis in NASH. GR-MD-02 is a complex carbohydrate that binds to galectin- 3 and galectin-1 proteins. Galectin-3 protein is a prominent galectin expressed in immune cells and markedly increased in inflammation. It has recently been implicated in the pathogenesis of fibrosis in several murine disease models. ${ }^{84-86}$ Traber et al. ${ }^{87}$ demonstrated that treatment of mice with GR-MD-02 reduced fibrosis by over 2.5-fold in comparison to controls. Phase I human data showed improvement in serological tests indicative of liver fibrosis and improvement in liver stiffness on FibroScan, with a favorable safety profile. ${ }^{88}$ Phase II trials are currently recruiting.

\section{Other investigational agents}

Simtuzumab, a monoclonal antibody against lysyl oxidaselike-2 (LOXL2), is a profibrotic enzyme abundant in hepatocytes. In vitro studies demonstrate reduced hepatic fibrosis and rapid reversal of fibrosis with simtuzumab therapy. ${ }^{89}$ Simtuzumab has already showed promising results when applied to patients with primary sclerosing cholangitis and is currently being studied in patients with NASH and F2-F3 fibrosis. ${ }^{90}$ Liraglutide is a glucagon-like peptide 1 inhibitor used for type 2 diabetes, and has been shown to improve liver histology in small trials. ${ }^{91}$ In a larger randomized controlled trial with 80 patients, 6 months of liraglutide therapy has been shown to reduce liver fat compared to placebo. ${ }^{92}$ A strong correlation between weight loss and improvement in steatosis was noted, similar to the results for pioglitazone therapy. Patients who lost the most weight $(10 \mathrm{~kg})$ experienced a decrease in liver fat from $17.0 \%$ to $6.9 \%$ on MRS. These agents are very promising and many more approved and preclinical drugs are under investigation in the pipeline for NASH.

\section{Conclusions}

The disease spectrum of NALFD encompasses a wide range of patients, and it will continue to represent a public health burden of epidemic proportion. Unfortunately, the current therapies have limited efficacy, although sustained weight loss can alter the natural history of disease. At this writing, a pipeline of novel therapeutic agents is in development and we expect increasing options for clinicians to treat this patient population in the coming years. Future pharmacologic strategies for NASH treatment will be multi-pronged and target metabolic pathways including insulin sensitivity, fatty acid synthesis and oxidation, and various mechanisms of decreasing inflammation. This is a burgeoning and hopeful field of study and we eagerly await the results from numerous clinical trials in early phases. Ultimately, the horizon is bright for clinicians who treat NASH.

\section{Conflict of interest}

Dr. Gutierrez has served on speakers' bureaus for Gilead, Merck, Bristol-Meyers Squibb, AbbVie, Intercept, Grifols and 
Alexion; has served as a consultant for BMS, Intercept, AbbVie and Gilead Sciences, Inc.; and has received research support from AbbVie, Synageva, Bristol-Myers Squibb, Gilead Sciences, Inc., Intercept, Janssen, and Merck. The others have no conflict of interest to declare.

\section{Author contributions}

Contributed equally to the work of literature review and manuscript writing (JV, AC, MM, KG), provided mentorship/ oversight and edited the manuscript (JG), provided final editing, formatting, and submission (JV).

\section{References}

[1] Peery AF, Dellon ES, Lund J, Crockett SD, McGowan CE, Bulsiewicz WJ, et al Burden of gastrointestinal disease in the United States: 2012 update. Gastroenterology 2012;143:1179-1187.e1-3. doi: 10.1053/j.gastro.2012.08.002.

[2] Zezos P, Renner EL. Liver transplantation and non-alcoholic fatty liver disease. World J Gastroenterol 2014;20:15532-15538. doi: 10.3748/wjg. v20.i42.15532.

[3] Ludwig J, Viggiano TR, McGill DB, Oh BJ. Nonalcoholic steatohepatitis: Mayo Clinic experiences with a hitherto unnamed disease. Mayo Clin Proc 1980;55: 434-438.

[4] McPherson S, Hardy T, Henderson E, Burt AD, Day CP, Anstee OM. Evidence of NAFLD progression from steatosis to fibrosing-steatohepatitis using paired biopsies: implications for prognosis and clinical management. J Hepatol 2015;62:1148-1155. doi: 10.1016/j.jhep.2014.11.034.

[5] Angulo P. Nonalcoholic fatty liver disease. N Engl J Med 2002;346: 1221-1231. doi: 10.1056/NEJMra011775.

[6] Powell EE, Cooksley WG, Hanson R, Searle J, Halliday JW, Powell LW. The natural history of nonalcoholic steatohepatitis: a follow-up study of fortytwo patients for up to 21 years. Hepatology 1990;11:74-80. doi: 10.1002/ hep.1840110114.

[7] Ong JP, Younossi ZM. Epidemiology and natural history of NAFLD and NASH. Clin Liver Dis 2007;11:1-16, vii. doi: 10.1016/j.cld.2007.02.009.

[8] Adler M, Schaffner F. Fatty liver hepatitis and cirrhosis in obese patients. Am J Med 1979;67:811-816. doi: 10.1016/0002-9343(79)90740-X.

[9] Bugianesi E, Leone N, Vanni E, Marchesini G, Brunello F, Carucci P, et al. Expanding the natural history of nonalcoholic steatohepatitis: from cryptogenic cirrhosis to hepatocellular carcinoma. Gastroenterology 2002;123: 134-140. doi: 10.1053/gast.2002.34168.

[10] Loomba R, Sanyal AJ. The global NAFLD epidemic. Nat Rev Gastroentero Hepatol 2013;10:686-690. doi: 10.1038/nrgastro.2013.171.

[11] Qureshi K, Abrams GA. Prevalence of biopsy-proven non-alcoholic fatty liver disease in severely obese subjects without metabolic syndrome. Clin Obes 2016;6:117-123. doi: 10.1111/cob.12132.

[12] Vernon G, Baranova A, Younossi ZM. Systematic review: the epidemiology and natural history of non-alcoholic fatty liver disease and non-alcoholic steatohepatitis in adults. Aliment Pharmacol Ther 2011;34:274-285. doi: 10.1111/j.1365-2036.2011.04724.x.

[13] Tilg $H$, Moschen AR. Evolution of inflammation in nonalcoholic fatty liver disease: the multiple parallel hits hypothesis. Hepatology 2010;52: 1836-1846. doi: 10.1002/hep.24001.

[14] Yilmaz Y. Review article: is non-alcoholic fatty liver disease a spectrum, or are steatosis and non-alcoholic steatohepatitis distinct conditions? Aliment Pharmacol Ther 2012;36:815-823. doi: 10.1111/apt.12046.

[15] Day CP, James OF. Steatohepatitis: a tale of two "hits"? Gastroenterology 1998;114:842-845. doi: 10.1016/S0016-5085(98)70599-2

[16] Fabbrini E, Sullivan S, Klein S. Obesity and nonalcoholic fatty liver disease: biochemical, metabolic, and clinical implications. Hepatology 2010;51: 679-689. doi: 10.1002/hep.23280.

[17] Rolo AP, Teodoro JS, Palmeira CM. Role of oxidative stress in the pathogenesis of nonalcoholic steatohepatitis. Free Radic Biol Med 2012;52:59-69. doi: 10.1016/j.freeradbiomed.2011.10.003.

[18] Pan JJ, Fallon MB. Gender and racial differences in nonalcoholic fatty liver disease. World J Hepatol 2014;6:274-283. doi: 10.4254/wjh.v6.i5.274.

[19] Sheth SG, Gordon FD, Chopra S. Nonalcoholic steatohepatitis. Ann Intern Med 1997;126:137-145. doi: 10.7326/0003-4819-126-2-199701150-00008.

[20] Charatcharoenwitthaya P, Lindor KD, Angulo P. The spontaneous course of liver enzymes and its correlation in nonalcoholic fatty liver disease. Dig Dis Sci 2012;57:1925-1931. doi: 10.1007/s10620-012-2098-3.

[21] Chalasani N, Younossi Z, Lavine JE, Diehl AM, Brunt EM, Cusi K, et al. The diagnosis and management of non-alcoholic fatty liver disease: practice guideline by the American Gastroenterological Association, American
Association for the Study of Liver Diseases, and American College of Gastroenterology. Gastroenterology 2012;142:1592-1609. doi: 10.1053/j.gastro. 2012.04.001.

[22] Feldstein AE, Wieckowska A, Lopez AR, Liu YC, Zein NN, McCullough AJ. Cytokeratin-18 fragment levels as noninvasive biomarkers for nonalcoholic steatohepatitis: a multicenter validation study. Hepatology 2009;50: 1072-1078. doi: 10.1002/hep.23050.

[23] Yilmaz Y. Systematic review: caspase-cleaved fragments of cytokeratin 18- the promises and challenges of a biomarker for chronic liver disease. Aliment Pharmacol Ther 2009;30:1103-1109. doi: 10.1111/j.1365-2036. 2009.04148.x

[24] Hernaez R, Lazo M, Bonekamp S, Kamel I, Brancati FL, Guallar E, et al. Diagnostic accuracy and reliability of ultrasonography for the detection of fatty liver: a meta-analysis. Hepatology 2011;54:1082-1090. doi: 10.1002/ hep. 24452.

[25] de Moura Almeida A, Cotrim HP, Barbosa DB, de Athayde LG, Santos AS, Bitencourt AG, et al. Fatty liver disease in severe obese patients: diagnostic value of abdominal ultrasound. World J Gastroenterol 2008;14:1415-1418. doi: 10.3748 /wjg. 14.1415 .

[26] Schwenzer NF, Springer F, Schraml C, Stefan N, Machann J, Schick F. Noninvasive assessment and quantification of liver steatosis by ultrasound, computed tomography and magnetic resonance. J Hepatol 2009;51:433-445. doi: $10.1016 /$ j.jhep.2009.05.023.

[27] Szczepaniak LS, Nurenberg P, Leonard D, Browning JD, Reingold JS, Grundy $S$, et al. Magnetic resonance spectroscopy to measure hepatic triglyceride content: prevalence of hepatic steatosis in the general population. Am J Physiol Endocrinol Metab 2005;288:E462-E468. doi: 10.1152/ ajpendo.00064.2004.

[28] Musso G, Gambino R, Cassader M, Pagano G. Meta-analysis: natural history of non-alcoholic fatty liver disease (NAFLD) and diagnostic accuracy of non-invasive tests for liver disease severity. Ann Med 2011;43:617-649. doi: $10.3109 / 07853890.2010 .518623$.

[29] Zhang E, Wartelle-Bladou C, Lepanto L, Lachaine J, Cloutier G, Tang A. Costutility analysis of nonalcoholic steatohepatitis screening. Eur Radiol 2015; 25:3282-3294. doi: 10.1007/s00330-015-3731-2.

[30] Myers RP, Pomier-Layrargues G, Kirsch R, Pollett A, Duarte-Rojo A, Wong D, et al. Feasibility and diagnostic performance of the FibroScan $X L$ probe for liver stiffness measurement in overweight and obese patients. Hepatology 2012;55:199-208. doi: 10.1002/hep.24624.

[31] Kleiner DE, Brunt EM, Van Natta M, Behling C, Contos MJ, Cummings OW, et al. Design and validation of a histological scoring system for nonalcoholic fatty liver disease. Hepatology 2005;41:1313-1321. doi: 10.1002/hep. 20701.

[32] Promrat K, Kleiner DE, Niemeier HM, Jackvony E, Kearns M, Wands JR, et al. Randomized controlled trial testing the effects of weight loss on nonalcoholic steatohepatitis. Hepatology 2010;51:121-129. doi: 10.1002/hep.23276.

[33] Belfort R, Harrison SA, Brown K, Darland C, Finch J, Hardies J, et al. A placebo-controlled trial of pioglitazone in subjects with nonalcoholic steatohepatitis. N Engl J Med 2006;355:2297-2307. doi: 10.1056/NEJMoa060326.

[34] Johnson NA, Sachinwalla T, Walton DW, Smith K, Armstrong A, Thompson $\mathrm{MW}$, et al. Aerobic exercise training reduces hepatic and visceral lipids in obese individuals without weight loss. Hepatology 2009;50:1105-1112. doi: $10.1002 /$ hep. 23129

[35] Zivkovic AM, German JB, Sanyal AJ. Comparative review of diets for the metabolic syndrome: implications for nonalcoholic fatty liver disease. Am J Clin Nutr 2007;86:285-300.

[36] Mummadi RR, Kasturi KS, Chennareddygari S, Sood GK. Effect of bariatric surgery on nonalcoholic fatty liver disease: systematic review and metaanalysis. Clin Gastroenterol Hepatol 2008;6:1396-1402. doi: 10.1016/j. cgh.2008.08.012.

[37] Yalamanchili $K$, Saadeh S, Klintmalm GB, Jennings LW, Davis GL. Nonalcoholic fatty liver disease after liver transplantation for cryptogenic cirrhosis or nonalcoholic fatty liver disease. Liver Transpl 2010;16:431-439. doi: 10.1002/ It. 22004.

[38] Charlton MR, Burns JM, Pedersen RA, Watt KD, Heimbach JK, Dierkhising RA. Frequency and outcomes of liver transplantation for nonalcoholic steatohepatitis in the United States. Gastroenterology 2011;141:1249-1253. doi: 10.1053/j.gastro.2011.06.061.

[39] Afzali A, Berry K, Ioannou GN. Excellent posttransplant survival for patients with nonalcoholic steatohepatitis in the United States. Liver Transpl 2012; 18:29-37. doi: 10.1002/It.22435.

[40] Harrison SA, Fecht W, Brunt EM, Neuschwander-Tetri BA. Orlistat for overweight subjects with nonalcoholic steatohepatitis: A randomized, prospective trial. Hepatology 2009;49:80-86. doi: 10.1002/hep.22575.

[41] Zelber-Sagi S, Kessler A, Brazowsky E, Webb M, Lurie Y, Santo M, et al. A double-blind randomized placebo-controlled trial of orlistat for the treatment of nonalcoholic fatty liver disease. Clin Gastroenterol Hepatol 2006;4: 639-644. doi: 10.1016/j.cgh.2006.02.004.

[42] Bugianesi E, Gentilcore E, Manini R, Natale S, Vanni E, Villanova N, et al. A randomized controlled trial of metformin versus vitamin $\mathrm{E}$ or prescriptive 
diet in nonalcoholic fatty liver disease. Am J Gastroenterol 2005;100:10821090. doi: 10.1111/j.1572-0241.2005.41583.x.

[43] Loomba R, Lutchman G, Kleiner DE, Ricks M, Feld JJ, Borg BB, et al. Clinical trial: pilot study of metformin for the treatment of non-alcoholic steatohepatitis. Aliment Pharmacol Ther 2009;29:172-182. doi: 10.1111/j.1365-2036. 2008.03869.x.

[44] Shields WW, Thompson KE, Grice GA, Harrison SA, Coyle WJ. The effect of metformin and standard therapy versus standard therapy alone in nondiabetic patients with insulin resistance and nonalcoholic steatohepatitis (NASH): a pilot trial. Therap Adv Gastroenterol 2009;2:157-163. doi: 10. $1177 / 1756283 \times 09105462$

[45] de Oliveira CP, Stefano JT, de Siqueira ER, Silva LS, de Campos Mazo DF, Lima VM, et al. Combination of $\mathrm{N}$-acetylcysteine and metformin improves histological steatosis and fibrosis in patients with non-alcoholic steatohepatitis. Hepatol Res 2008;38:159-165. doi: 10.1111/j.1872-034X.2007.00215.x.

[46] Lavine JE, Schwimmer JB, Van Natta ML, Molleston JP, Murray KF, Rosenthal P, et al. Effect of vitamin $\mathrm{E}$ or metformin for treatment of nonalcoholic fatty liver disease in children and adolescents: the TONIC randomized controlled trial. JAMA 2011;305:1659-1668. doi: 10.1001/jama.2011.520.

[47] Garinis GA, Fruci B, Mazza A, De Siena M, Abenavoli S, Gulletta E, et al. Metformin versus dietary treatment in nonalcoholic hepatic steatosis: a randomized study. Int J Obes (Lond) 2010;34:1255-1264. doi: 10.1038/ ijo.2010.40.

[48] Bhat A, Sebastiani G, Bhat M. Systematic review: Preventive and therapeutic applications of metformin in liver disease. World J Hepatol 2015;7: 1652-1659. doi: 10.4254/wjh.v7.i12.1652.

[49] Ratziu V, Giral P, Jacqueminet S, Charlotte F, Hartemann-Heurtier A, Serfaty $L$, et al. Rosiglitazone for nonalcoholic steatohepatitis: one-year results of the randomized placebo-controlled Fatty Liver Improvement with Rosiglitazone Therapy (FLIRT) Trial. Gastroenterology 2008;135:100-110. doi: 10. 1053/j.gastro.2008.03.078.

[50] Sanyal AJ, Chalasani N, Kowdley KV, McCullough A, Diehl AM, Bass NM, et al. Pioglitazone, vitamin $\mathrm{E}$, or placebo for nonalcoholic steatohepatitis. N Engl ] Med 2010;362:1675-1685. doi: 10.1056/NEJMoa0907929.

[51] Boettcher E, Csako G, Pucino F, Wesley R, Loomba R. Meta-analysis: pioglitazone improves liver histology and fibrosis in patients with non-alcoholic steatohepatitis. Aliment Pharmacol Ther 2012;35:66-75. doi: 10.1111/j. 1365-2036.2011.04912.x.

[52] Miller ER 3rd, Pastor-Barriuso R, Dalal D, Riemersma RA, Appel L], Guallar E. Meta-analysis: high-dosage vitamin $\mathrm{E}$ supplementation may increase allcause mortality. Ann Intern Med 2005;142:37-46. doi: 10.7326/00034819-142-1-200501040-00110.

[53] Gerss ], Köpcke W. The questionable association of vitamin E supplementation and mortality-inconsistent results of different meta-analytic approaches. Cell Mol Biol (Noisy-le-grand) 2009;55 Suppl:OL1111-1120.

[54] Georgescu EF, Georgescu M. Therapeutic options in non-alcoholic steatohepatitis (NASH). Are all agents alike? Results of a preliminary study. J Gastrointestin Liver Dis 2007;16:39-46.

[55] Chatrath $H$, Vuppalanchi $R$, Chalasani N. Dyslipidemia in patients with nonalcoholic fatty liver disease. Semin Liver Dis 2012;32:22-29. doi: 10.1055/ s-0032-1306423.

[56] El-Serag HB, Johnson ML, Hachem C, Morgana RO. Statins are associated with a reduced risk of hepatocellular carcinoma in a large cohort of patients with diabetes. Gastroenterology 2009;136:1601-1608. doi: 10.1053/j. gastro.2009.01.053.

[57] Parker HM, Johnson NA, Burdon CA, Cohn JS, O'Connor HT, George J. Omega-3 supplementation and non-alcoholic fatty liver disease: a systematic review and meta-analysis. J Hepatol 2012;56:944-951. doi: 10.1016/j. jhep.2011.08.018.

[58] Scorletti E, Bhatia L, McCormick KG, Clough GF, Nash K, Hodson L, et al. Effects of purified eicosapentaenoic and docosahexaenoic acids in nonalcoholic fatty liver disease: results from the Welcome study. Hepatology 2014; 60:1211-1221. doi: 10.1002/hep.27289.

[59] Lefebvre P, Chinetti G, Fruchart JC, Staels B. Sorting out the roles of PPAR alpha in energy metabolism and vascular homeostasis. J Clin Invest 2006; 116:571-580. doi: 10.1172/JCI27989.

[60] Zambon A, Gervois P, Pauletto P, Fruchart JC, Staels B. Modulation of hepatic inflammatory risk markers of cardiovascular diseases by PPAR-alpha activators: clinical and experimental evidence. Arterioscler Thromb Vasc Biol 2006; 26:977-986. doi: 10.1161/01.ATV.0000204327.96431.9a.

[61] Staels B, Rubenstrunk A, Noel B, Rigou G, Delataille P, Millatt LJ, et al. Hepatoprotective effects of the dual peroxisome proliferator-activated receptor alpha/delta agonist, GFT505, in rodent models of nonalcoholic fatty liver disease/nonalcoholic steatohepatitis. Hepatology 2013;58:1941-1952. doi: $10.1002 /$ hep.26461.

[62] Ratziu V, Harrison SA, Francque S, Bedossa P, Lehert P, Serfaty L, et al. Elafibranor, an agonist of the peroxisome proliferator-activated receptor- $\alpha$ and $-\delta$, induces resolution of nonalcoholic steatohepatitis without fibrosis worsening. Gastroenterology 2016;150:1147-1159.e5. doi: 10.1053/j. gastro.2016.01.038.
[63] Porez G, Prawitt J, Gross B, Staels B. Bile acid receptors as targets for the treatment of dyslipidemia and cardiovascular disease. J Lipid Res 2012;53: 1723-1737. doi: 10.1194/jlr.R024794.

[64] Mudaliar S, Henry RR, Sanyal AJ, Morrow L, Marschall HU, Kipnes M, et al. Efficacy and safety of the farnesoid $X$ receptor agonist obeticholic acid in patients with type 2 diabetes and nonalcoholic fatty liver disease. Gastroenterology 2013;145:574-582.e1. doi: 10.1053/j.gastro.2013.05.042.

[65] Neuschwander-Tetri BA, Loomba R, Sanyal AJ, Lavine JE, Van Natta ML, Abdelmalek MF, et al. Farnesoid $\mathrm{X}$ nuclear receptor ligand obeticholic acid for non-cirrhotic, non-alcoholic steatohepatitis (FLINT): a multicentre, randomised, placebo-controlled trial. Lancet 2015;385:956-965. doi: 10.1016/ S0140-6736(14)61933-4.

[66] Hirschfield GM, Mason A, Luketic V, Lindor K, Gordon SC, Mayo M, et al. Efficacy of obeticholic acid in patients with primary biliary cirrhosis and inadequate response to ursodeoxycholic acid. Gastroenterology 2015;148: 751-761.e8. doi: 10.1053/j.gastro.2014.12.005.

[67] Ueno $Y$, Ohmi T, Yamamoto M, Kato N, Moriguchi Y, Kojima M, et al. Orallyadministered caspase inhibitor PF-03491390 is retained in the liver for prolonged periods with low systemic exposure, exerting a hepatoprotective effect against alpha-fas-induced liver injury in a mouse model. J Pharmacol Sci 2007;105:201-205. doi: 10.1254/jphs.SC0070207.

[68] Feldstein AE, Canbay A, Angulo P, Taniai M, Burgart LJ, Lindor KD, et al. Hepatocyte apoptosis and fas expression are prominent features of human nonalcoholic steatohepatitis. Gastroenterology 2003;125:437-443. doi: 10. 1016/S0016-5085(03)00907-7.

[69] Barreyro FJ, Holod S, Finocchietto PV, Camino AM, Aquino JB, Avagnina A, et al. The pan-caspase inhibitor Emricasan (IDN-6556) decreases liver injury and fibrosis in a murine model of non-alcoholic steatohepatitis. Liver Int 2015;35:953-966. doi: 10.1111/liv.12570.

[70] Shiffman M, Freilich B, Vuppalanchi R, Watt K, Burgess G, Morris M, et al. A placebo-controlled, multicenter, double-blind, randomised trial of emricasan in subjects with non-alcoholic fatty liver disease (NAFLD) and raised transaminases. J Hepatology 2015;62:S282. doi: 10.1016/S0168-8278 (15)30191-4.

[71] Konikoff FM, Gilat T. Effects of fatty acid bile acid conjugates (FABACs) on biliary lithogenesis: potential consequences for non-surgical treatment of gallstones. Curr Drug Targets Immune Endocr Metabol Disord 2005;5: 171-175. doi: 10.2174/1568008054064904

[72] Dobrzyn P, Dobrzyn A, Miyazaki M, Cohen P, Asilmaz E, Hardie DG, et al. Stearoyl-CoA desaturase 1 deficiency increases fatty acid oxidation by activating AMP-activated protein kinase in liver. Proc Natl Acad Sci U S A 2004; 101:6409-6414. doi: 10.1073/pnas.0401627101.

[73] Safadi R, Konikoff FM, Mahamid M, Zelber-Sagi S, Halpern M, Gilat T, et al. The fatty acid-bile acid conjugate Aramchol reduces liver fat content in patients with nonalcoholic fatty liver disease. Clin Gastroenterol Hepatol 2014;12:2085-2091.e1. doi: 10.1016/j.cgh.2014.04.038.

[74] Saiman Y, Friedman SL. The role of chemokines in acute liver injury. Front Physiol 2012;3:213. doi: 10.3389/fphys.2012.00213.

[75] Schwabe RF, Bataller R, Brenner DA. Human hepatic stellate cells express CCR5 and RANTES to induce proliferation and migration. Am J Physiol Gastrointest Liver Physiol 2003;285:G949-G958. doi: 10.1152/ajpgi.00215. 2003.

[76] Seki E, De Minicis S, Gwak GY, Kluwe J, Inokuchi S, Bursill CA, et al. CCR1 and CCR5 promote hepatic fibrosis in mice. J Clin Invest 2009;119:1858-1870. doi: $10.1172 /$ jci37444.

[77] Seki E, de Minicis S, Inokuchi S, Taura K, Miyai K, van Rooijen N, et al. CCR2 promotes hepatic fibrosis in mice. Hepatology 2009;50:185-197. doi: 10. 1002/hep.22952.

[78] Mitchell C, Couton D, Couty JP, Anson M, Crain AM, Bizet V, et al. Dual role of CCR2 in the constitution and the resolution of liver fibrosis in mice. Am J Pathol 2009;174:1766-1775. doi: 10.2353/ajpath.2009.080632.

[79] Berres ML, Koenen RR, Rueland A, Zaldivar MM, Heinrichs D, Sahin H, et al. Antagonism of the chemokine $\mathrm{Ccl} 5$ ameliorates experimental liver fibrosis in mice. J Clin Invest 2010;120:4129-4140. doi: 10.1172/JCI41732.

[80] Karlmark KR, Weiskirchen R, Zimmermann HW, Gassler N, Ginhoux F, Weber $C$, et al. Hepatic recruitment of the inflammatory Gr1+ monocyte subset upon liver injury promotes hepatic fibrosis. Hepatology 2009;50:261-274. doi: $10.1002 /$ hep. 22950.

[81] Miura K, Yang L, van Rooijen N, Ohnishi H, Seki E. Hepatic recruitment of macrophages promotes nonalcoholic steatohepatitis through CCR2. Am J Physiol Gastrointest Liver Physiol 2012;302:G1310-G1321. doi: 10.1152/ ajpgi.00365.2011.

[82] Friedman S, Sanyal A, Goodman Z, Lefebvre E, Gottwald M, Fischer L, et al. Efficacy and safety study of cenicriviroc for the treatment of non-alcoholic steatohepatitis in adult subjects with liver fibrosis: CENTAUR Phase $2 b$ study design. Contemp Clin Trials 2016;47:356-365. doi: 10.1016/j.cct. 2016.02.012.

[83] Thompson M, Saag M, DeJesus E, Gathe J, Lalezari J, Landay AL, et al. A 48 -week randomized phase $2 b$ study evaluating cenicriviroc versus efavirenz in treatment-naive HIV-infected adults with C-C chemokine 
receptor type 5-tropic virus. AIDS 2016;30:869-878, doi: 10.1097/QAD. 0000000000000988 .

[84] Yang RY, Rabinovich GA, Liu FT. Galectins: structure, function and therapeutic potential. Expert Rev Mol Med 2008;10:e17. doi: 10.1017/ S1462399408000719.

[85] Henderson NC, Sethi T. The regulation of inflammation by galectin-3. Immunol Rev 2009;230:160-171. doi: 10.1111/j.1600-065X.2009.00794.x.

[86] Forsman $\mathrm{H}$, Islander $U$, Andréasson $E$, Andersson A, Onnheim K, Karlström A et al. Galectin 3 aggravates joint inflammation and destruction in antigeninduced arthritis. Arthritis Rheum 2011;63:445-454. doi: 10.1002/art. 30118.

[87] Traber PG, Chou H, Zomer E, Hong F, Klyosov A, Fiel MI, et al. Regression of fibrosis and reversal of cirrhosis in rats by galectin inhibitors in thioacetamideinduced liver disease. PLoS One 2013;8:e75361. doi: 10.1371/journal. pone. 0075361 .

[88] Harrison SA, Chalasani NP, Lawitz E, Marri S, Noureddin M, Sanyal AJ, et al. Early phase 1 clinical trial results of GR-MD-02, a galectin-3 inhibitor, in patients having non-alcoholic steatohepatitis (NASH) with advanced fibrosis. Hepatology 2014;60:225A-226A.
[89] Ikenaga N, Peng ZW, Vaid KA, Liu SB, Yoshida S, Sverdlov DY, et al. Selective targeting of lysyl oxidase-like 2 (LOXL2) suppresses hepatic fibrosis progression and accelerates its reversal. Gut 2017. doi: 10.1136/gutjnl-2016312473.

[90] Bowlus CL, Montano-Loza AJ, Invernizzi P, Chazouillères O, Hirschfield G, Metselaar $\mathrm{HJ}$, et al. Liver stiffness measurement by transient elastography for the prediction of fibrosis in patients with primary sclerosing cholangitis in a randomized trial of simtuzumab. J Hepatol 2016;64:S434. doi: 10.1016/ S0168-8278(16)00710-8.

[91] Armstrong M], Gaunt P, Aithal GP, Barton D, Hull D, Parker R, et al. Liraglutide safety and efficacy in patients with non-alcoholic steatohepatitis (LEAN): a multicentre, double-blind, randomised, placebo-controlled phase 2 study. Lancet 2016;387:679-690. doi: 10.1016/S0140-6736 (15)00803-X.

[92] Petit JM, Cercueil JP, Loffroy R, Denimal D, Bouillet B, Fourmont C, et al. Effect of liraglutide therapy on liver fat content in patients with inadequately controlled type 2 diabetes. The Lira-NAFLD study. J Clin Endocrinol Metab 2017;102:407-415. doi: 10.1210/jc.2016-2775. 